University of Nebraska - Lincoln

DigitalCommons@University of Nebraska - Lincoln

\title{
Effect of Random Ethylene Comonomer on Relaxation of Flow- Induced Precursors in Isotactic Polypropylene
}

\author{
Benjamin Schammé \\ University of Nebraska-Lincoln \\ Eric Dargent \\ Normandie Université \\ Lucia Fernandez-Ballester \\ University of Nebraska-Lincoln, lucia.fernandez@unl.edu
}

Follow this and additional works at: https://digitalcommons.unl.edu/mechengfacpub

Part of the Mechanics of Materials Commons, Nanoscience and Nanotechnology Commons, Other Engineering Science and Materials Commons, and the Other Mechanical Engineering Commons

Schammé, Benjamin; Dargent, Eric; and Fernandez-Ballester, Lucia, "Effect of Random Ethylene Comonomer on Relaxation of Flow-Induced Precursors in Isotactic Polypropylene" (2017). Mechanical \& Materials Engineering Faculty Publications. 343.

https://digitalcommons.unl.edu/mechengfacpub/343

This Article is brought to you for free and open access by the Mechanical \& Materials Engineering, Department of at DigitalCommons@University of Nebraska - Lincoln. It has been accepted for inclusion in Mechanical \& Materials Engineering Faculty Publications by an authorized administrator of DigitalCommons@University of Nebraska Lincoln. 


\title{
Effect of Random Ethylene Comonomer on Relaxation of Flow-Induced Precursors in Isotactic Polypropylene
}

\author{
Benjamin Schammé, ${ }^{1,2}$ Eric Dargent, ${ }^{2}$ \\ and Lucia Fernandez-Ballester ${ }^{1}$
}

1 Department of Mechanical and Materials Engineering and Nebraska Center for Materials and Nanoscience,

University of Nebraska-Lincoln, Lincoln, Nebraska 68588, United States

2 UNIROUEN Normandie, INSA Rouen, CNRS, Groupe de Physique des Matériaux, Normandie Univ., 76000 Rouen, France

Corresponding author — Lucia Fernandez-Ballester, email lucia.fernandez@unl.edu

ORCID: Lucia Fernandez-Ballester: 0000-0001-6956-5104

\begin{abstract}
The effect of comonomer on structure and relaxation of flow-induced precursors was investigated in a series of isotactic polypropylene and random propyleneethylene copolymers. The polymers were subjected to flow by fiber pulling and allowed to relax above their nominal melting temperature for specific times. The type of morphology developed after cooling revealed whether flow-induced precursors were still present or the melt had fully reequilibrated. Precursors were longlived and, at fixed temperature, decayed significantly faster with higher ethylene content. The critical time for precursor relaxation followed an Arrhenius-type dependence with temperature. The apparent energy of activation for precursor dissolution decreased with increasing comonomer content, indicating that the ratelimiting step of the relaxation process becomes less difficult with higher ethylene fraction. This effect is attributed to ethylene co-units acting as disruptors of precursor structure and is discussed in terms of quasi-crystalline nature and characteristic chain stem length of precursor bundles.
\end{abstract}




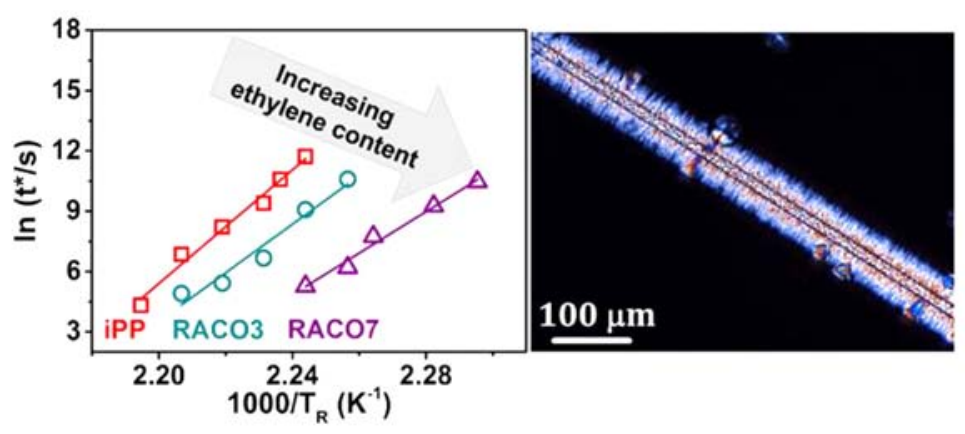

\section{Introduction}

Imposition of flow onto a polymer melt is well-known to have a tremendous impact on kinetics of crystallization, type of morphology that develops, and, consequently, final material properties. Flow-induced crystallization (FIC) can for instance trigger the formation of highly oriented crystallites and accelerate crystallization kinetics by orders of magnitude, resulting in an increase of the elastic modulus and tensile strength. ${ }^{1,2}$ Most processing techniques of polymers involve the application of strong flows, so understanding the basic mechanism of FIC is key to optimizing the final material properties of a particular resin.

Flow-induced precursors are at the heart of flow-induced crystallization, but they are still not fully understood. ${ }^{3-19}$ FIC oriented precursors are thought to be thread-like quasicrystalline structures that form in the melt during flow and which subsequently template the growth of oriented lamellae, thus dictating the final morphology. ${ }^{20,21}$ The precursors themselves are difficult to probe directly because of their small dimensions and because they are typically present in dilute concentrations, which oftentimes renders them undetectable due to experimental sensitivity limits. ${ }^{22,23} \mathrm{Never}-$ theless, FIC precursors have been detected directly with small-angle X-ray scattering (SAXS) and have also been correlated with an unusual upturn in birefringence during flow. ${ }^{10,24} \mathrm{~A}$ different approach for studying precursors involves indirect detection: by tracking the development of oriented crystallites which are templated on precursors, the presence of FIC precursors can be inferred. Real-time optical and X-ray measurements as well as exsitu examination of the final morphology have been used to expose oriented morphologies that indirectly reveal FIC precursors. ${ }^{7,9,25,26}$ Other indirect approaches use rheological measurements or differential scanning calorimetry to follow the increased rates of crystallization associated with flow-induced precursors. ${ }^{13,17}$ 
FIC precursors are known to survive for long times at high temperatures even above the nominal melting temperature. ${ }^{7}$ Several studies have investigated the relaxation behavior of flow-induced precursors with the objective of revealing information about their structure and nature. Generally, it has been found that relaxation of FIC precursors follows an Arrhenius-type dependence with an apparent energy of activation that is much larger than the flow activation energy, so the rate-limiting step of relaxation is not controlled by the rheological processes in the melt. ${ }^{7-9,13,26-28} \mathrm{~A}$ few studies have probed FIC precursors as a function of processing conditions. Balzano et al. found that the imposed shear stress influenced the aspect ratio of oriented precursors of isotactic polypropylene (iPP) which, in turn, determined their stability at high temperatures. ${ }^{12} \mathrm{Hamad}$ and coworkers observed that FIC precursors created at increasing levels of specific work needed longer annealing times to fully decay. ${ }^{13}$ Furthermore, above certain specific work, the stability of precursors saturated and their response to annealing was independent of flow conditions. Cavallo et al. also reported longer lifetimes for precursors that had formed at higher shear rates, but they established that the rate-determining step of precursor relaxation was unaffected by the level of applied shear rate. ${ }^{9}$ Only a few studies have probed the role of molecular characteristics onto structure and relaxation of FIC precursors. For example, Azzurri et al. found that the relaxation time of precursors of both isotactic polystyrene (iPS) and isotactic polybutene (iPBu) increased with increasing molecular weight $M_{w^{i}}$; however, the rate-limiting step for relaxation of precursors did not depend on $M_{w^{\prime}}$ implying that the structure of precursors was unchanged by differences in length of the polymer chains. ${ }^{7,8}$

The effect of comonomer content on structure and relaxation of flowinduced precursors of a random polypropylene-ethylene polymer has not previously been explored. Random comonomers can lead to significant changes in the type of crystalline structure that develops, the rates of crystallization, and the final material properties. Specifically, the incorporation of random ethylene co-units onto isotactic polypropylene results in improved impact resistance and mechanical properties at low temperatures as well as increased transparency. ${ }^{29}$ Random ethylene co-units act as defects and therefore hinder the process of crystallization under quiescent conditions, decreasing rate of crystallite growth, attainable degree of crystallinity, crystallization temperature, and melting temperature. ${ }^{30} \mathrm{Also}$, the presence of ethylene co-units has been associated with the development of $\gamma$-phase in addition to the more common $\alpha$-morph due to an increased number of short crystallizable sequences. ${ }^{30,31}$ Although early reports assumed that ethylene co-units were fully excluded from the crystal, ${ }^{32}$ it was later shown that the isotactic polypropylene crystal can include ethylene 
defects to certain extent. ${ }^{33,34}$ Flow-induced crystallization of random propylene-co-ethylene can also be affected by the presence of random co-units in the polymer chain, in terms of both formation of FIC precursors and subsequent crystalline growth from the precursors. ${ }^{35}$

In the current study, the impact of comonomer units on precursor structure and decay for random propylene-ethylene with up to $\sim 7 \%$ ethylene is investigated. To do so, precursors are formed by imposing flow via a fiber-pulling protocol; then, the relaxation behavior of the FIC precursors is examined to provide insights into the rate-determining step of their decay and into the structure of the precursors themselves.

\section{Experimental Section}

\subsection{Materials}

Three semicrystalline polymers from Borealis were studied: an isotactic polypropylene homopolymer (Borealis HD234CF) and two propylene/ethylene random copolymers (Borealis RD204CF and RD208CF, respectively), synthesized by bulk polymerization in the gas phase using a Ziegler-Natta catalyst. ${ }^{29}$ Their molecular and physical characteristics have been previously reported in the literature ${ }^{29,36}$ and are summarized in Table 1. Differential scanning calorimetry scans can be found in the Supporting Information. Here, the homopolymer is denoted as "iPP" while the copolymers are denoted as "RACO3" and "RACO7", according to their respective ethylene content of 3.4 and $7.3 \mathrm{~mol} \%$. All three grades possess a weight-average molecular weight $M_{w}$ of $310 \mathrm{~kg} / \mathrm{mol}$ and a polydispersity index $M_{w} / M_{n}$ of 3.4 .

Glass-coated fibers Flexstrand 110EM13347 with diameter of $17 \pm 1$ $\mu \mathrm{m}$ were kindly provided by Fiber Glass Industries and used as received. The fibers were examined with a Quanta 200 FEG environmental scanning electron microscope and were found to have a smooth surface without observable defects or particles. Control crystallization experiments were performed which verified that these glass fibers do not induce preferential crystallization-called transcrystallinity-on the fiber surface under quiescent conditions, i.e., in the absence of flow.

Polypropylene films of approximately $250 \mu \mathrm{m}$ of thickness were compression molded at $215^{\circ} \mathrm{C}$ for $2 \mathrm{~min}$ in a Specac hydraulic press and then allowed to slowly cool. Rectangular pieces of $10 \mathrm{~mm} \times 5 \mathrm{~mm}$ were cut from the compression-molded films. To prepare the polymer-fiber composite, a single glass fiber was first carefully extracted from a bundle containing approximately 2000 fibers, and it was inspected to ensure that no bending had occurred. The glass fiber was placed between two $250 \mu \mathrm{m}$ thick polymer films. The assembly was then examined to verify that the embedded 


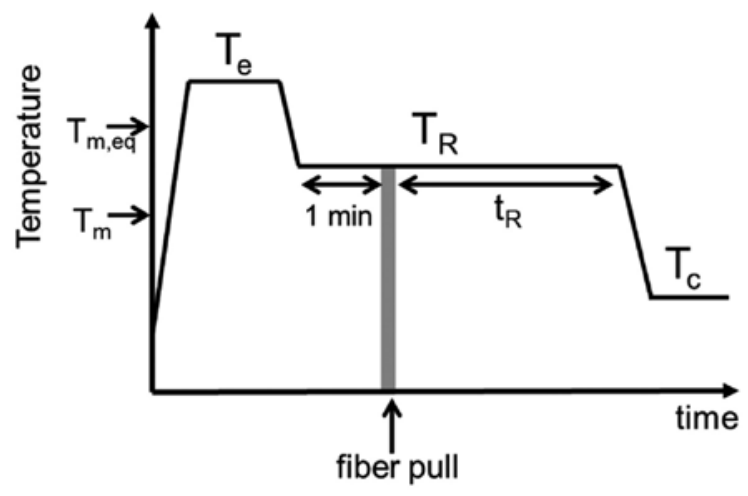

Figure 1. Thermomechanical protocol for relaxation experiments.

fiber was completely straight without any observable curvature. The polymer-fiber composite was subsequently sandwiched between a glass slide and a cover glass which had previously been cleaned with ethanol. The assembly was placed in a Mettler Toledo FP82HT hot stage coupled with a FP90 control system.

\subsection{Thermomechanical Protocol}

The thermal and flow protocol is schematized in Figure 1. First, the assembly was heated to an erase temperature $T_{\mathrm{e}}=215^{\circ} \mathrm{C}$, which is above the equilibrium melting point of iPP $\left(T_{\mathrm{m}^{\prime} \text { eq }}=208^{\circ} \mathrm{C}\right) .{ }^{37} \mathrm{~A}$ slight pressure was then applied onto the coverslip to ensure that the fiber was well embedded within the polymer and to avoid air bubbles. After pressing, the temperature was held at $215{ }^{\circ} \mathrm{C}$ for $t_{\mathrm{e}}=5 \mathrm{~min}$ to erase the previous thermal history of the polymer. Then, the temperature was decreased at a rate of 20 ${ }^{\circ} \mathrm{C} / \mathrm{min}$ to the chosen relaxation temperature $T_{\mathrm{R}^{\prime}}$ which was always selected to be above the nominal melting temperature $T_{m}$ (Table 1). After equilibration at $T_{\mathrm{R}}$ for $1 \mathrm{~min}$, the fiber was manually pulled through the molten polymer at a linear velocity of $5-10 \mathrm{~mm} / \mathrm{s}$ over a distance of $5-10 \mathrm{~mm}$. It

Table 1. Molecular and Physical Properties of the Materials from the Literature 29,36

\begin{tabular}{llllll} 
polymer & grade & $\begin{array}{l}\text { ethylene content } \\
(\text { mol \%) }\end{array}$ & $\begin{array}{l}X_{c} \\
(\%)^{b}\end{array}$ & $\begin{array}{l}T_{m} \\
\left({ }^{\circ} \mathrm{C}\right)^{b}\end{array}$ & $\begin{array}{l}T_{c} \\
\left({ }^{\circ} \mathrm{C}\right)^{b}\end{array}$ \\
\hline iPP & HD234CF & 0 & 49.5 & 164 & 110 \\
RACO3 & RD204CF & 3.4 & 41.3 & 153 & 105 \\
RACO7 & RD208CF & 7.3 & 33.9 & 139 & 98 \\
\hline
\end{tabular}

a. Measured by NMR.

b. From differential scanning calorimetry at $10^{\circ} \mathrm{C} / \mathrm{min}$. 
has previously been found that small differences in pulling velocity or total displacement that may occur when manually pulling the fiber do not appear to affect the results of flow relaxation experiments. ${ }^{7}$ Care was taken to ensure that the movement of the fiber occurred solely in the direction of its axis. After cessation of flow, the sample was allowed to relax at $T_{\mathrm{R}}$ for a specified relaxation time $t_{\mathrm{R}}$. It should be noted that both flow and relaxation occur at temperatures well above the nominal melting temperature, i.e., at temperatures where lamellar growth rates are negligible.

After the relaxation time $t_{R}$ had elapsed, the sample was quickly cooled down at $20^{\circ} \mathrm{C} / \mathrm{min}$ to a suitable crystallization temperature $T_{c^{\prime}}$ chosen such that linear growth rates were relatively high and bulk nucleation densities were relatively low $\left(135-138{ }^{\circ} \mathrm{C}\right.$ for iPP, $128^{\circ} \mathrm{C}$ for RACO3, and $120-122^{\circ} \mathrm{C}$ for RACO7). A reference time $t_{0}$ was started once $T_{c}$ was reached. Polarized optical micrographs were obtained every minute up to $t_{0}=30$ min with an Olympus BX51 polarizing optical microscope at 20x magnification. Different areas of the sample were examined in order to account for any possible inhomogeneity in the glass fiber coating. At the end of the experiment, the assembly was removed from the hot stage and air-cooled. The composite was then removed from the slides, and its final thickness was measured.

The axial movement of a fiber in a molten polymer imposes a shear rate $\dot{\gamma}$ with a cylindrical symmetry. Monasse ${ }^{38}$ showed that the shear rate $\dot{\gamma}$ at a distance $r$ from the fiber axis can be expressed as

$$
\dot{\gamma}=\frac{1-n}{n} \frac{1}{r^{1 / n}}\left[\frac{1}{r_{f}^{1-1 / n}-r_{e}^{1-1 / n}}\right] \mathrm{V}_{f}
$$

where $n$ is the exponent in the viscosity power law equation, $r_{f}$ is the radius of the glass fiber $(8.5 \mu \mathrm{m}), r_{\mathrm{e}}$ is the external radius (half thickness of the polymer film), $r$ is the radius, and $V_{f}$ is the velocity of pulling. According to Eq. 1, the shear rate under our flow conditions reaches values in the order of several hundreds of $\mathrm{s}^{-1}$ near the surface of the fiber.

\section{Results}

\subsection{Flow-Induced Crystallization Morphology}

Imposition of flow by axial movement of a glass fiber embedded in an iPP matrix can result in subsequent growth of a shear-induced oriented morphology near the fiber surface (Figure 2b). This oriented structure is not caused by transcrystallinity effects on the fiber surface: control quiescent experiments-in which no flow is applied-developed only a bulk spherulitic morphology throughout the polymer, and there was no preferential 


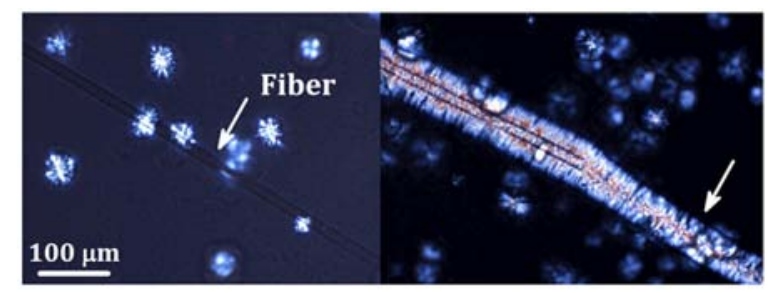

Figure 2. (a) Spherulitic morphology formed after $15 \mathrm{~min}$ at $T_{\mathrm{c}}=135^{\circ} \mathrm{C}$ in a quiescent experiment where no flow has been imposed. (b) Cylindritic morphology formed after $15 \mathrm{~min}$ at $T_{\mathrm{c}}=135^{\circ} \mathrm{C}$ in a shear experiment where the glass fiber was pulled $\left(T_{\mathrm{R}}=172.5^{\circ} \mathrm{C}, t_{\mathrm{R}}=40 \mathrm{~min}\right)$.

crystalline growth on the fiber surface (Figure 2a). In contrast, a cylindritic oriented morphology can develop in experiments where the fiber has been pulled due to the shear flow imposed by the moving fiber (Figure $2 b$ ). The highly oriented structures can also be observed in the wake of the fiber (white arrow in Figure 2b), further confirming that they were not due to transcrystallinity on the fiber surface. ${ }^{27,39}$ When shear flow resulted in oriented crystallization, development of oriented crystallites only took place close to the fiber surface, where the highest levels of shear rate occurred. Further from the fiber surface, only spherulites typical of quiescent conditions were obtained due to the rapid decrease of shear rate with distance from the fiber. Both the cylindritic and the spherulitic structures developed with identical linear growth rate $G$, indicating that lamellar growth rate is not affected by the previous flow history. ${ }^{7}$

In shear experiments, a small birefringent zone around the fiber was briefly observed while the fiber was being pulled and can be attributed to increased orientation of polymer chains while subjected to high shear rates. Even though that melt birefringence quickly disappears after cessation of flow, the effects of shear on final morphology can persist for very long times, in agreement with other studies. For example, iPP still retains some orientation after a relaxation time of $\sim 15 \mathrm{~min}$ at $180{ }^{\circ} \mathrm{C}$ and of $\sim 3 \mathrm{~h}$ at $175^{\circ} \mathrm{C}$ (see Relaxation Experiments section). Long-lived effects of flow have also been reported by other authors, such as relaxation times between 1 and 32 min at $190{ }^{\circ} \mathrm{C} .9,26,28,40,41$ In other words, the conformation of polymer chains in the melt is distorted by the imposition of flow, and such distortion can persist for relatively long times, determining the type of semicrystalline morphology that forms upon cooling down.

\subsection{Determination of Critical Holding Time $\boldsymbol{t}^{*}$}

The growth of a cylindritic morphology around the fiber after cessation of flow is a clear and exceptionally sensitive indicator of remaining perturbation in the polymer melt, i.e., of the presence of flow-induced precursors (FIC precursors). The 
development of an oriented morphology implies that even if the sample was allowed to relax for a given relaxation time $t_{\mathrm{R}^{\prime}}$ complete re-equilibration of the polymer melt was not attained. In contrast, the absence of high nucleation density around the fiber for experiments with large enough relaxation times $t_{R}$ indicates that the melt was able to fully reach a re-equilibrated state.

To quantify the melt re-equilibration process, a critical relaxation time $t^{*}$ is defined as the holding time necessary to completely erase the effect of the applied flow. Here, $t^{*}$ at each relaxation temperature $T_{\mathrm{R}}$ is calculated as the average of two values: the maximum relaxation time $t^{\star}{ }_{\text {MAX }}$ for which some preferential nucleation on the fiber surface is still observed upon cooling to $T_{c}$ and the minimum relaxation time $t^{\star}{ }_{\text {MIN }}$ for which only a spherulitic morphology is detected.

Increasing the relaxation time $t_{R}$ at a fixed relaxation temperature $T_{R}$ generally resulted in a decline of nucleation density near the fiber. For example, increasing $t_{\mathrm{R}}$ from $5 \mathrm{~s}$ to $15 \mathrm{~min}$ at $T_{\mathrm{R}}=180{ }^{\circ} \mathrm{C}$ resulted in a partial disappearance of flow-induced precursors, as inferred from the observed morphologies (Figure $3 a-c$ ). Once $t_{\mathrm{R}}$ exceeded the critical time $t^{*}$, the melt memory due to flow was fully erased and only spherulites developed throughout (i.e., $t_{\mathrm{R}}=20 \mathrm{~min}$ in Figure $3 \mathrm{~d}$ ).

\subsection{Relaxation Experiments}

The critical holding time $t^{\star}$ was determined at different relaxation temperatures $T_{\mathrm{R}}$ by examining the final morphology that appeared after allowing
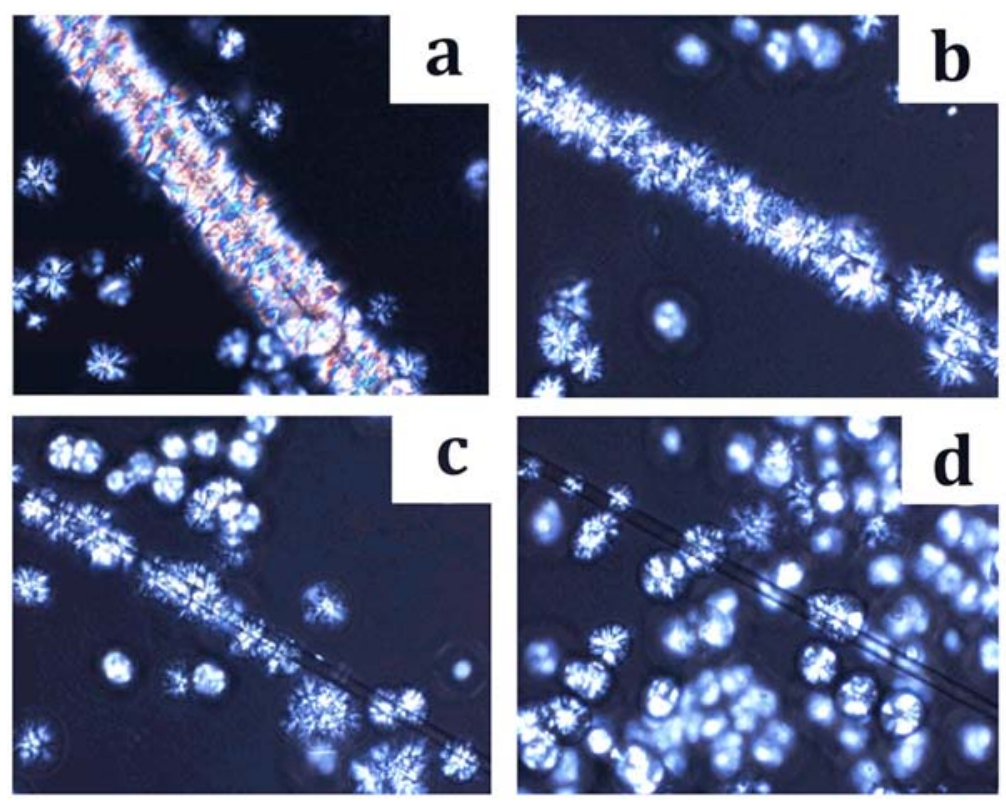

Figure 3. Morphological evolution of iPP after $15 \mathrm{~min}$ at $T_{\mathrm{c}}=135^{\circ} \mathrm{C}$ in fiber pull experiments with $T_{R}=180^{\circ} \mathrm{C}$ and relaxation times $t_{R}$ of (a) $5 \mathrm{~s}$, (b) $10 \mathrm{~min}$, (c) 15 min, and (d) $20 \mathrm{~min}$. 
relaxation to occur for a specific relaxation time $t_{\mathrm{R}}$ and then cooling to a suitable crystallization temperature $T_{C}$. In this way, the morphological outcome of each fiber pull experiment was classified to construct a morphological map for each type of material. Selection criteria were based on Figure 3: extensive cylindritic morphology was denominated "high orientation" (Figure 3a,b), decreased nucleation along the fiber-but still preferentialwas regarded as "low orientation" (Figure 3c), and the presence of only bulk spherulitic morphology was denominated "spherulitic" (Figure 3d). It should be noted that the distinction between high and low orientation was qualitative only. The morphological map of iPP is shown in Figure 4, while those of RACO3 and RACO7 can be found in the Supporting Information. The dashed line in Figure 4 represents the critical time $t^{\star}$ calculated as the average between the maximum holding time $t^{*}{ }_{\text {MAX }}$ for observing some cylindritic morphology and the minimum time $t^{*}{ }_{\text {MIN }}$ for which only a spherulitic morphology is obtained. The values for $t^{\star}{ }_{\text {MAX }}$ and $t^{\star}{ }_{\text {MIN }}$ at different relaxation temperatures $T_{\mathrm{R}}$ for all three materials are reported in Table $\mathbf{2}$.

For a given material, the strong temperature dependence of the critical times $t^{\star}$ (dashed line in Figure 4 ) indicates that the lifetime of flow-induced precursors is a highly sensitive function of relaxation temperature $T_{\mathrm{R}}$. As an example, the time required to fully erase the shear-induced nucleation for iPP increases from $\sim 16 \mathrm{~min}$ at $180^{\circ} \mathrm{C}$ to more than $30 \mathrm{~h}$ at 172.5 ${ }^{\circ} \mathrm{C}$. Such strong temperature dependence is consistent with previous studies; for example, work on poly(1-butene) found that the critical time increased by 3 orders of magnitude when the relaxation temperature was decreased by $10^{\circ} \mathrm{C} .{ }^{7}$

For a given relaxation temperature $T_{\mathrm{R}^{\prime}}$ the critical time for disappearance of the oriented morphology $t^{*}$ significantly decreases with increasing comonomer content. For example, at $172.5^{\circ} \mathrm{C}$, iPP needs more than $30 \mathrm{~h}$ to

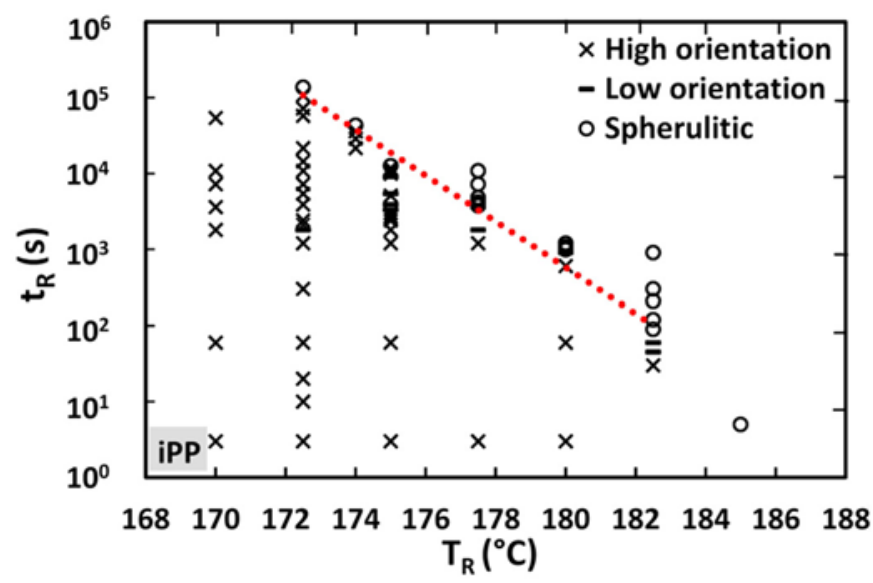

Figure 4. iPP morphological map for relaxation experiments. Dashed line corresponds to a linear fit of the calculated critical relaxation times $t^{\star}$. 
Table 2. Critical Holding Times $t^{*}$ at Different $T_{R}$ for iPP, RACO3, and RACO7a

\begin{tabular}{llll} 
& \multicolumn{3}{c}{$t^{*}(s)$} \\
\cline { 2 - 4 }$T_{R}\left({ }^{\circ} \mathrm{C}\right)$ & iPP & RACO3 & RACO7 \\
\hline 182.5 & $60-90$ & $120-150$ & \\
180 & $900-990$ & $210-240$ & \\
177.5 & $3600-3750$ & $750-810$ & \\
175 & $11700-12600$ & & \\
174 & $36000-43200$ & & $180-210$ \\
172.5 & $108000-136800$ & $8520-9000$ & $480-510$ \\
170 & & $36000-43200$ & $2250-2325$ \\
168.5 & & & $10320-10800$ \\
165 & & & $30600-39600$ \\
162.5 & & & \\
\hline
\end{tabular}

a. The first and second value in each pair correspond to $t^{\star}{ }_{M} \mathrm{AX}$ maximum time for some cylindritic morphology) and $t^{*}{ }_{M} I N$ minimum time for only spherulitic morphology), respectively.

completely relax the oriented morphology, while RACO3 and RACO7 only need $\sim 2.5 \mathrm{~h}$ and $3.5 \mathrm{~min}$, respectively (Table 2). Likewise, with increasing ethylene content, the temperature of relaxation $T_{\mathrm{R}}$ needs to be lowered in order to obtain similar values of critical relaxation time $t^{\star}$. It was also found that the highest temperature $T_{\mathrm{R}}$ for which oriented crystallization could be obtained-using the shortest possible holding times-decreases with increasing comonomer content. Indeed, it was not possible to obtain cylindritic structures after fiber pulling for $T_{\mathrm{R}}$ above $182.5,180$, and $172.5^{\circ} \mathrm{C}$ for iPP, RACO3, and RACO7, respectively. Such a threshold on $T_{\mathrm{R}}$ may have been caused in part by limitations in cooling speed: at the highest relaxation temperatures where $t^{\star}$ is on the order of $\sim 5 \mathrm{~s}$ or smaller, the experimental setup cannot be cooled fast enough to prevent some relaxation of flow-induced structures during the early stages of cooling. Additionally, it is possible that flow-induced structures are not able to form at the highest temperatures if crystallizable sequences are not long enough, particularly as the comonomer content increases.

The apparent activation energy $E_{\mathrm{a}}$ for complete disappearance of flowinduced structures was found to decrease with increasing copolymer content. To calculate $E$ a, the average critical time $t^{\star}$ was first plotted against the inverse of temperature in an Arrhenius plot (Figure 5). A set of straight lines was obtained, so Eq. 2 was used to obtain values of $E_{\mathrm{a}}$ for each material:

$$
\ln \left(t^{\star}\right)=\ln (A)-\frac{E_{\mathrm{a}}}{R}\left(\frac{1}{T}\right)
$$




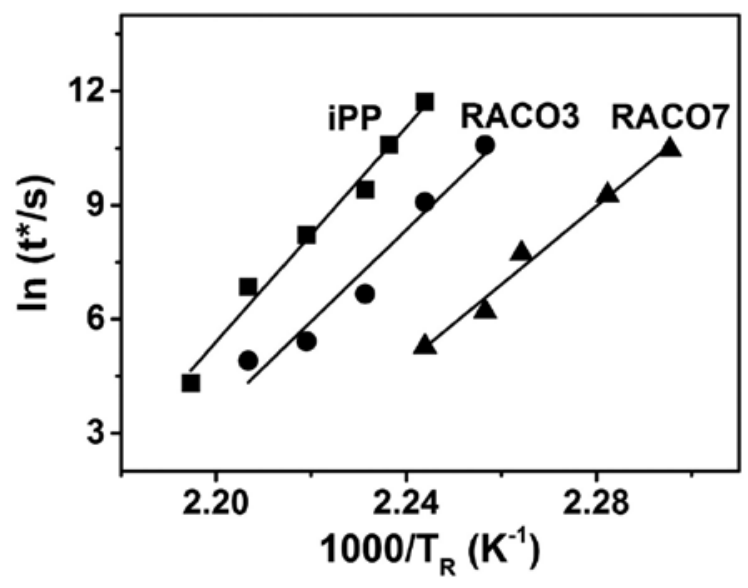

Figure 5. Arrhenius plot of critical holding times $t^{\star}$ as a function of relaxation temperature $T_{\mathrm{R}}$ for iPP $(\mathbf{\square})$, RACO3 $(\bullet)$, and RACO7 $(\mathbf{\Delta})$.

where $t^{\star}$ (in $\mathrm{s}$ ) is the critical relaxation time, $A$ is a preexponential factor, $R$ is the gas constant $\left(8.314 \mathrm{~J} \mathrm{~K}^{-1} \mathrm{~mol}^{-1}\right)$, and $T$ is the absolute temperature (in K). Energies of activation of $1180 \pm 60,1000 \pm 50$, and $860 \pm 40 \mathrm{~kJ} / \mathrm{mol}$ were obtained for iPP, RACO3, and RACO7, respectively.

\section{Discussion}

The development of an oriented morphology near the fiber surface is an extremely sensitive indicator of the presence of oriented precursors that formed during strong enough flows. These oriented precursors are thought to be crystalline or quasi-crystalline thread-like nuclei, although their exact structure remains the subject of discussion. In the present experiments, flow-induced precursors form during flow in the region subjected to the highest level of shear stress-near the fiber surface. After cessation of flow, the oriented precursors can undergo a gradual disappearance process if the polymer melt is held at sufficiently high relaxation temperature for a long time. The dissolution of precursors is reflected in a decrease in oriented morphologies developed after cooling to the crystallization temperature.

The Arrhenius-type dependence with temperature of the critical times for relaxation provides some insight into the manner in which oriented precursors decay. The process of flow-induced precursor relaxation is believed to occur by detachment of polymer chain segments from the oriented nuclei and their subsequent diffusion into the melt. The apparent energies of activation for precursor relaxation of iPP, RACO3, and RACO7 are much larger than the energy of activation for viscous flow ( 44 kJ/mol for iPP) ${ }^{42}$ Therefore, it appears that detachment of a chain stem from an oriented 
nuclei is the limiting step in the process of precursor relaxation-not diffusion of the detached stem into the melt. This observation is in agreement with studies of relaxation in iPP, iPS, and iPBu. ${ }^{7,9,26}$

The decrease of apparent activation energies $E_{\mathrm{a}}$ with increasing ethylene content indicates that the rate of the relaxation process is altered by the presence of comonomer. This may be attributed to the disruption of the structure of oriented precursors and thus to the process of chain stem detachment from quasi-crystalline precursor bundles. It is well-known that random ethylene co-units in polypropylene play a major role by acting as perturbations of the resulting crystalline structure, so the reduction of $E_{\mathrm{a}}$ with increasing ethylene content suggests that those random co-units are also effective at perturbing the morphological nature of the precursors.

The apparent activation energies $E_{\mathrm{a}}$ can be used to obtain information about the structure of flow-induced precursors, which have been proposed to consist of partially ordered bundles of chains with a quasi-crystalline nature and a characteristic bundle length $L_{S} \cdot{ }^{8}$ In this model, it is envisioned that precursors decay by having chain segments of length $L_{\mathrm{s}}$ disengage from the precursor bundles. The length $L_{s}$ may then be determined as

$$
L_{\mathrm{s}}=\frac{E_{\mathrm{a}}}{\Delta H_{\mathrm{m}}^{0}} \times L_{\mathrm{u}}
$$

where $L_{u}$ corresponds to the length of the repeating unit along the $c$-axis in the crystalline lattice, $E_{\mathrm{a}}$ is the apparent activation energy for disappearance of oriented precursors, and $\Delta H_{m}^{0}$ is the melting enthalpy of the polymer crystals. For iPP, $L_{u}$ is $\sim 0.22 \mathrm{~nm}^{43}$ and the thermodynamic melting enthalpy of its crystals $\Delta H_{\mathrm{m}}^{0}$ is $8.7 \mathrm{~kJ} / \mathrm{mol} .{ }^{44}$ However, if the melting enthalpy of a perfect iPP crystal is used in calculations for random copolymers, their detaching chain length $L_{S}$ may be underestimated. Indeed, random ethylene co-units are known to be partially included into the crystalline phase of iPP, locally distorting it and resulting in a decrease of the energy required to melt it. ${ }^{34,45}$ Consequently, the melting enthalpies of copolymer crystallites are projected to be lower than $8.7 \mathrm{~kJ} / \mathrm{mol}$.

For random copolymers, the exact dependence of the melting enthalpy of the crystalline phase with the fraction of incorporated comonomer units is unknown. One approach for obtaining an estimate of the melting enthalpy is to use the Sanchez-Eby theory of copolymers, which considers an excess free energy $\varepsilon$ associated with comonomers incorporated into the crystalline phase as defects. ${ }^{46}$ Although the variation of the melting enthalpy with $\varepsilon$ remains elusive, some authors have assumed a linear dependency $\Delta H_{\text {cryst,cop }}=\Delta H_{\text {cryst,homo }}-\varepsilon X_{c}$, where $\Delta H_{\text {cryst,cop }}$ is the heat of fusion per mole of crystalline copolymer, $\Delta H_{\text {cryst,homo }}$ is the heat of fusion per mole of crystalline homopolymer $(8.7 \mathrm{~kJ} / \mathrm{mol})$, and $X_{c}$ is the mole fraction 
of ethylene co-units in the crystalline phase of the copolymer. ${ }^{47,48}$ For polypropylene-ethylene copolymers, Alamo et al. experimentally obtained data for $X_{c}$ and calculated a penalty energy $\varepsilon$ of $\sim 2.94 \mathrm{~kJ} / \mathrm{mol} .{ }^{34,47}$ Using these literature values, it is estimated that the $\Delta H_{\text {cryst,RACO }}$ would only decrease by $\sim 0.9 \%$ when compared to $8.7 \mathrm{~kJ} / \mathrm{mol}$ of the iPP homopolymer, indicating that the ethylene counits only slightly distort the energy landscape of the crystalline structure. The corresponding detaching stem lengths $L_{\mathrm{S}}$ are 30, 25, and $22 \mathrm{~nm}$ for iPP, RACO3, and RACO7, respectively (Table 3).

Another approach to estimate the melting enthalpy of $100 \%$ crystalline phase $\Delta H_{\text {cryst,cop }}$ involves measuring the experimental heat of fusion of a given sample with differential scanning calorimetry and then determining its crystallinity with an alternative experimental technique. Laihonen et al. normalized the experimental heat of fusion by the crystallinity obtained from wide-angle X-ray diffraction and determined that $\Delta H_{\text {cryst,cop }}$ decreased by $\sim 30-40 \mathrm{~J} / \mathrm{g}$ per $10 \%$ of ethylene content. ${ }^{49}$ Using Laihonen's result, a $\Delta H_{\text {cryst,RACO } 7}$ of $\sim 7.7 \mathrm{~kJ} / \mathrm{mol}$ can be estimated for RACO7, i.e., a steeper decrease than that calculated with $\varepsilon$. The resulting values of $L_{\mathrm{s}}$ still show a decrease with increasing copolymer percentage: 30, 27, and $24 \mathrm{~nm}$ for iPP, RACO3, and RACO7 (Table 3). Finally, in another study, Alamo et al. also obtained measurements of experimental enthalpy of fusion and corresponding NMR crystallinities for a series of polypropylene-ethylene copolymers. ${ }^{34}$ If the experimental melting enthalpies are normalized by their corresponding ${ }^{13} \mathrm{C}$ NMR crystallinities, an even stronger decrease in enthalpy with ethylene content is predicted: for RACO7, $\Delta H_{\text {cryst,RACO7 }}$ would be $\sim 6.6 \mathrm{~kJ} / \mathrm{mol}$. In this case, however, the obtained detaching stem lengths $L_{\mathrm{s}}$ display an almost constant value of approximately $30 \mathrm{~nm}$ (Table 3).

While the decrease in $E_{\mathrm{a}}$ indicates that the process of chain stem detachment from quasi-crystalline bundles becomes less difficult with increasing ethylene content, the exact interpretation in terms of structural parameters of precursors is complicated by the uncertainty in $\Delta H_{\text {cryst,cop }}$. The values of $L_{S}$ obtained with $\varepsilon$ and with Laihonen's data suggest that ethylene counits mainly disrupt structure of precursors by decreasing the

Table 3. Values of Apparent Energy of Activation for Precursor Relaxation $E_{a}$ and Stem Length $\mathrm{L}_{\mathrm{s}}$ Calculated with $\Delta \mathrm{H}_{\text {cryst,cop }}$ Estimated Using Excess Free Energy $\varepsilon$, a Decrease of $30-40 \mathrm{~J} / \mathrm{g}$ per $10 \mathrm{~mol} \%$ Ethylene, ${ }^{49}$ and Data on Heat of Fusion and on ${ }^{13} \mathrm{C}$ NMR Crystallinities $^{34}$ (further details are available in the Supporting Information).

\begin{tabular}{lllll} 
sample & $\begin{array}{l}E_{a} \\
(\mathrm{~kJ} / \mathrm{mol})\end{array}$ & $\begin{array}{l}L_{s, \text { excess free energy }} \\
(\mathrm{nm})\end{array}$ & $\begin{array}{l}L_{s, \text { Laihonen }} \\
(\mathrm{nm})^{49}\end{array}$ & $\begin{array}{l}L_{s, \text { Alamo }} \\
(\mathrm{nm})^{34}\end{array}$ \\
\hline iPP & 1180 & 30 & 30 & 30 \\
RACO3 & 1000 & 25 & 27 & 30 \\
RACO7 & 860 & 22 & 25 & 29 \\
\hline
\end{tabular}




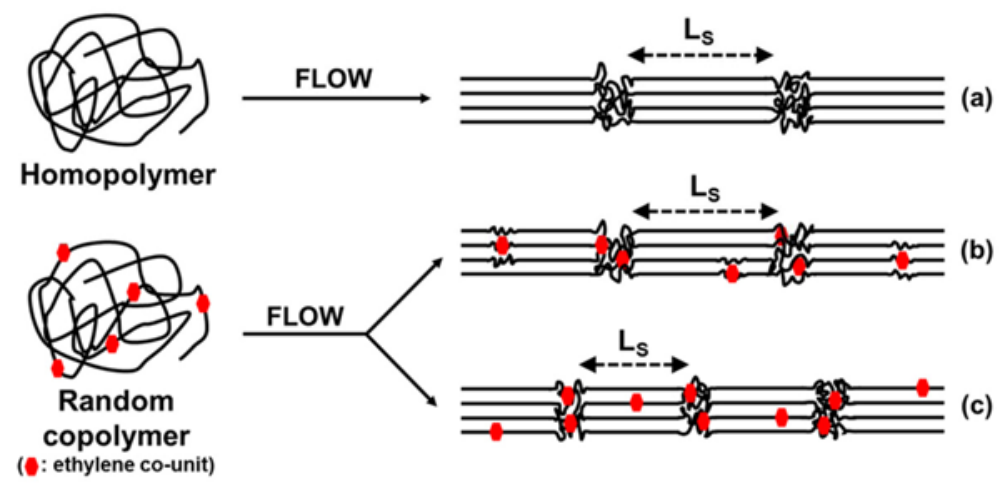

Figure 6. Schematic of flow-induced precursors of (a) a homopolymer and (b, c) a copolymer. (a) The homopolymer forms precursors with a characteristic detaching stem length $L_{s}$. (b) The copolymer forms precursors with $L_{s}$ similar to that of the homopolymer if its counits predominantly increase the degree of imperfection within the internal structure of bundles (decrease in $\Delta H_{\text {cryst,cop }}$ ). (c) The copolymer forms precursors with decreased $L_{\mathrm{s}}$ if the presence of comonomer mainly decreases the average length of precursor bundles $\left(\Delta H_{\text {cryst,cop }}\right.$ nearly invariant).

average length of precursor bundles - and thus, the length of chain stem $L_{s}$ that must detach during decay (schematically illustrated in Figure 6, compare $\mathrm{a}$ and $\mathrm{c}$ ). In contrast, $L_{\mathrm{s}}$ determined by normalizing with ${ }^{13} \mathrm{C} N \mathrm{NMR}$ crystallinities suggests that ethylene comonomers predominantly disturb precursor structure by increasing the internal degree of imperfection of quasi-crystalline bundles (Figure 6 , compare $a$ and $b$ ). This divergence may be due to the fact that ${ }^{13} \mathrm{C}$ NMR crystallinity considers the fraction of ordered 3/1 helical sites (crystallites) but does not take into account how perfectly packed those helices are. ${ }^{34}$ Imperfections in packing of helices can result in decreased calorimetry or wide-angle X-ray diffraction crystallinities without significantly changing the magnitude of NMR crystallinity, yielding differing estimates of $\Delta H_{\text {cryst,cop }}$ (and $L_{s}$ ) depending on which experimental technique is used.

Because of the uncertainty in melting enthalpy of copolymer crystals, it is not possible to discern between the effect of comonomer units on precursors as depicted in Figure 6b,c. Also, qualitative arguments can be made for both possible scenarios. On one hand, if the characteristic lamellar thickness of a polymer is considered to be related to precursor stem length $L_{s^{\prime}}$ a reduction in $L_{s}$ with increasing coethylene content-as estimated from calculations based on Sanchez-Eby and Laihonen (Table 3) - would be expected. Indeed, lamellar thickness in polypropylene-ethylene random copolymers generally decreases with increasing ethylene percentage, ${ }^{29,50-52}$ although invariance of lamellar thickness with comonomer content has also been reported. ${ }^{33}$ The decrease in crystallite thickness 
with higher comonomer percentage is generally explained as follows: because a fraction of ethylene units must be excluded from the polypropylene crystals, a resin with higher copolymer content has a smaller average length of crystallizable sequences which can then only participate in lamellae of reduced thickness. On the other hand, it can be hypothesized that due to their quasi-crystalline nature, flow-induced precursors are able to accommodate ethylene counits more easily than a "regular" $\alpha$-crystal because defects impose less strain on their structure. In other words, the more disordered structure of precursors-as compared to iPP $\alpha$-phase-would experience less disruption due to inclusion of ethylene defects and would not be as limited by available crystallizable lengths, leading to invariance of $L_{S}$ with increasing copolymer content as computed from ${ }^{13} \mathrm{C}$ NMR data.

The activation energy $E_{\mathrm{a}}$ and, consequently, the detaching stem length $L_{S}$ obtained here for iPP are somewhat greater than in previous relaxation experiments of iPP ( $30 \mathrm{~nm}$ vs $\sim 7 \mathrm{~nm}$ ). Notably, an $L_{\mathrm{s}} \sim 30 \mathrm{~nm}$ for iPP is commensurate with the periodicity of layer-like precursors of iPP previously inferred from real-time small-angle $X$-ray scattering $(\sim 43 \mathrm{~nm})^{3}$ and similar to the detaching stem length obtained for relaxation of other types of polymers, namely polyoxyethylene and ipolybutene $(\sim 20 \mathrm{~nm}){ }^{8,27}$ The value of $30 \mathrm{~nm}$ is also comparable to the lamellar thickness of iPP characteristic of relatively high crystallization temperature: under quiescent conditions at $152{ }^{\circ} \mathrm{C}$, a lamellar thickness of $\sim 20 \mathrm{~nm}$ and corresponding long period of $\sim 30 \mathrm{~nm}$ would be expected, ${ }^{48}$ while early kebabs grown after flow at low undercoolings can display a long period of up to $\sim 60 \mathrm{~nm} .{ }^{53}$ The larger activation energy $E_{\mathrm{a}}$ obtained here for iPP $(\sim 1180 \mathrm{~kJ} / \mathrm{mol}$ vs a range of $\sim 122-350 \mathrm{~kJ} / \mathrm{mol}$ in other reports $)^{9,13,26-28}$ may be due to differences in experimental protocol. Indeed, discrepancies in $E_{\mathrm{a}}$ are ubiquitous in the literature and have been ascribed to variability in the experimental approach. For example, Janeschitz-Kriegl obtained an $E_{\mathrm{a}} \sim 224 \mathrm{~kJ} / \mathrm{mol}$ for iPB, ${ }^{26}$ about one-third of the value of $\sim 720 \mathrm{~kJ} / \mathrm{mol}$ previously found by Azzurri. ${ }^{7}$ For iPP, Nazari et al. obtained an apparent activation energy of $122 \mathrm{~kJ} / \mathrm{mol},{ }^{13}$ much smaller than that of $334 \mathrm{~kJ} / \mathrm{mol}$ previously reported by Janeschitz-Kriegl. ${ }^{26}$ These disparities were attributed to using different criteria when determining $t^{*}$-assessment of complete disappearance of orientation vs a criterion of partial decay-and to employing different techniques to detect precursors, which can lead to dissimilar definitions of "presence of precursors". Experimental conditions such as flow geometry, range of shear rate, and range of relaxation temperature also vary widely among different studies, but it is unclear whether sufficiently large variations could generate structural differences in precursors that affect the process of stem detachment and the apparent energy of activation. For example, Cavallo et al. reported that changing shear rate $\dot{\gamma}$ from 16 to $32 \mathrm{~s}^{-1}$ does not noticeably affect the 
apparent activation energy for relaxation of precursors in iPP (i.e., the ratedetermining step for relaxation is independent of shear rate within the explored range), although the critical time for disappearance of the precursors is larger for higher shear rates. ${ }^{9}$ In the current study, fiber pulling can impose shear rates on the order of several hundreds of $\mathrm{s}^{-1}$, but it is undetermined whether such difference in flow conditions would significantly affect precursor structure. Likewise, here precursors have formed in a range of temperatures. However, the role of shearing temperature on the structure of flow-induced precursors has not previously been explored, and consequently, whether it has a significant impact on the rate-limiting step of relaxation remains unknown.

\section{Conclusion}

The relaxation behavior of flow-induced precursors in iPP provides information about their nature and underlying structure. These oriented precursors are key to the effects of flow-induced crystallization but are extremely difficult to directly probe due to their small size and to their scarce concentration in the melt. In this study, the presence or absence of flow-induced precursors was deduced from the type of semicrystalline morphology that forms near the surface of a previously pulled fiber, i.e., in the region that was subjected to the highest shear rate. The process of decay of precursors was explored by first imposing flow and then allowing the melt to relax at relatively high temperatures $T_{\mathrm{R}}$ for specific relaxation times $t_{\mathrm{R}}$ before cooling down to a crystallization temperature $T_{c}$.

It was found that the process of decay of flow-induced precursors is affected by the presence of random ethylene counits in the polypropylene chain. The critical times for precursor relaxation $t^{\star}$ followed an Arrheniustype dependence with temperature, and the apparent energy of activation for precursor dissolution $E_{\mathrm{a}}$ clearly decreased with increasing ethylene content. Such a decrease indicated that the limiting step in the process of precursors decay is effectively altered by the presence of random comonomer units. $E_{\mathrm{a}}$ values for all three materials were much larger than the activation energy for viscous flow of iPP so, in agreement with other studies, it is deduced that the limiting step in precursor decay is detachment of a chain stem from an oriented nuclei-not diffusion of the detached stem into the melt.

The decrease of apparent activation energy $E_{\mathrm{a}}$ indicates that the process of chain stem detachment becomes easier with increasing ethylene content. This effect is attributed to disruption of the structure of precursors caused by the random ethylene counits. Oriented precursors are envisioned as quasicrystalline bundles from which chain stems of a characteristic length 
$L_{\mathrm{S}}$ become detached - with an associated enthalpy-during the relaxation process. The enthalpy of crystallization of polypropylene-random-ethylene copolymers $\Delta H_{\text {cryst,cop }}$ is however not well-known, leading to some uncertainty when estimating the detaching stem length $L_{s}$. Estimations of $\Delta H_{\text {cryst,cop }}$ based on available experimental data suggest two possible scenarios: one in which ethylene counits mainly disrupt structure of precursors by decreasing the average length of precursor bundles-and therefore the detaching stem length $L_{\mathrm{s}}$-and another one in which ethylene comonomers primarily disturb precursor structure by increasing the degree of imperfection of the quasi-crystalline bundles.

Acknowledgments - The research was performed in part in the Nebraska Nanoscale Facility: National Nanotechnology Coordinated Infrastructure and the $\mathrm{Ne}$ braska Center for Materials and Nanoscience, which are supported by the National Science Foundation under Award ECCS 1542182 and the Nebraska Research Initiative. M. L. Auad is thanked for performing differential scanning calorimetry. The authors declare no competing financial interest.

\section{References}

1) Kalay, G.; Bevis, M. J. Processing and physical property relationships in injection-molded isotactic polypropylene 0.2. Morphology and crystallinity. J. Polym. Sci., Part B: Polym. Phys. 1997, 35 (2), 265-291.

2) Schrauwen, B. A. G.; Von Breemen, L. C. A.; Spoelstra, A. B.; Govaert, L. E.; Peters, G. W. M.; Meijer, H. E. H. Structure, deformation, and failure of flow-oriented semicrystalline polymers. Macromolecules 2004, 37 (23), 8618-8633.

3) Somani, R. H.; Yang, L.; Hsiao, B. S. Precursors of primary nucleation induced by flow in isotactic polypropylene. Phys. A 2002, 304 (1-2), 145-157.

4) Somani, R. H.; Yang, L.; Hsiao, B. S.; Fruitwala, H. Nature of shear-induced primary nuclei in iPP melt. J. Macromol. Sci., Part B: Phys. 2003, 42 (3), 515-531.

5) Somani, R. H.; Sics, I.; Hsiao, B. S. Thermal stability of shear-induced precursor structures in isotactic polypropylene by rheo-X-ray techniques with couette flow geometry. J. Polym. Sci., Part B: Polym. Phys. 2006, 44 (24), 3553-3570.

6) García Gutiérrez, M.-C.; Alfonso, G. C.; Riekel, C.; Azzurri, F. Spatially Resolved Flow-Induced Crystallization Precursors in Isotactic Polystyrene by Simultaneous Small- and Wide-Angle X-ray Microdiffraction. Macromolecules 2004, 37 (2), 478-485.

7) Azzurri, F.; Alfonso, G. C. Lifetime of shear-induced crystal nucleation precursors. Macromolecules 2005, 38 (5), 1723-1728.

8) Azzurri, F.; Alfonso, G. C. Insights into formation and relaxation of shearinduced nucleation precursors in isotactic polystyrene. Macromolecules 2008, $41(4), 1377-1383$. 
9) Cavallo, D.; Azzurri, F.; Balzano, L.; Funari, S. S.; Alfonso, G. C. Flow Memory and Stability of Shear-Induced Nucleation Precursors in Isotactic Polypropylene. Macromolecules 2010, 43 (22), 9394-9400.

10) Balzano, L.; Kukalyekar, N.; Rastogi, S.; Peters, G. W. M.; Chadwick, J. C. Crystallization and dissolution of flow-induced precursors. Phys. Rev. Lett. 2008, 100 (4), 048302.

11) Balzano, L. G.; Rastogi, S.; Peters, G. W. M. Crystallization and Precursors during Fast Short-Term Shear. Macromolecules 2009, 42 (6), 2088-2092.

12) Balzano, L.; Cavallo, D.; Van Erp, T. B.; Ma, Z.; Housmans, J.-W.; FernandezBallester, L.; Peters, G. W. M. Dynamics of fibrillar precursors of shishes as a function of stress. IOP Conf. Ser.: Mater. Sci. Eng. 2010, 14 (1), 012005.

13) Hamad, F. G.; Colby, R. H.; Milner, S. T. Lifetime of Flow-Induced Precursors in Isotactic Polypropylene. Macromolecules 2015, 48 (19), 7286-7299.

14) Balzano, L.; Ma, Z.; Cavallo, D.; van Erp, T. B.; Fernandez- Ballester, L.; Peters, G. W. M. Molecular Aspects of the Formation of Shish-Kebab in Isotactic Polypropylene. Macromolecules 2016, 49 (10), 3799-3809.

15) Liedauer, S.; Eder, G.; Janeschitz-Kriegl, H. On the Limitations of ShearInduced Crystallization in Polypropylene Melts. Int. Polym. Process. 1995, 10 (3), 243-250.

16) Kumaraswamy, G.; Kornfield, J. A.; Yeh, F. J.; Hsiao, B. S. Shear-enhanced crystallization in isotactic polypropylene. 3. Evidence for a kinetic pathway to nucleation. Macromolecules 2002, 35 (5), 1762-1769.

17) Nazari, B.; Rhoades, A. M.; Schaake, R. P.; Colby, R. H. Flow-Induced Crystallization of PEEK: Isothermal Crystallization Kinetics and Lifetime of Flow-Induced Precursors during Isothermal Annealing. ACS Macro Lett. 2016, 5 (7), 849-853.

18) Zhao, Y.; Hayasaka, K.; Matsuba, G.; Ito, H. In Situ Observations of FlowInduced Precursors during Shear Flow. Macromolecules 2013, 46 (1), $172-178$.

19) An, H.; Li, X.; Geng, Y.; Wang, Y.; Wang, X.; Li, L.; Li, Z.; Yang, C. Shear-Induced Conformational Ordering, Relaxation, and Crystallization of Isotactic Polypropylene. J. Phys. Chem. B 2008, 112 (39), 12256-12262.

20) Liedauer, S.; Eder, G.; Janeschitz-Kriegl, H.; Jerschow, P.; Geymayer, W.; Ingolic, E. On the Kinetics of Shear-Induced Crystallization in Polypropylene. Int. Polym. Process. 1993, 8 (3), 236-244.

21) Kumaraswamy, G.; Verma, R. K.; Issaian, A. M.; Wang, P.; Kornfield, J. A.; Yeh, F.; Hsiao, B. S.; Olley, R. H. Shear-enhanced crystallization in isotactic polypropylene Part 2. Analysis of the formation of the oriented "skin". Polymer 2000, 41 (25), 8931-8940.

22) Fernandez-Ballester, L.; Gough, T.; Meneau, F.; Bras, W.; Ania, F.; Francisco, J. C.; Kornfield, J. A. Simultaneous birefringence, smalland wide-angle $X$-ray scattering to detect precursors and characterize morphology development during flow-induced crystallization of polymers. J. Synchrotron Radiat. 2008, 15, 185-190.

23) Ma, Z.; Balzano, L.; Peters, G. W. M. Dissolution and Reemergence of FlowInduced Shish in Polyethylene with a Broad Molecular Weight Distribution. Macromolecules 2016, 49 (7), 2724-2730. 
24) Kumaraswamy, G.; Issaian, A. M.; Kornfield, J. A. Shear-enhanced crystallization in isotactic polypropylene. 1. Correspondence between in situ rheo-optics and ex situ structure determination. Macromolecules 1999, 32 (22), 7537-7547.

25) Fernandez-Ballester, L.; Thurman, D. W.; Kornfield, J. A. Realtime depth sectioning: Isolating the effect of stress on structure development in pressure-driven flow. J. Rheol. 2009, 53 (5), 1229-1254.

26) Janeschitz-Kriegl, H.; Eder, G. Shear Induced Crystallization, a Relaxation Phenomenon in Polymer Melts: A Re-Collection. J. Macromol. Sci., Part B: Phys. 2007, 46 (3), 591-601.

27) Alfonso, G. C.; Scardigli, P. Melt memory effects in polymer crystallization. Macromol. Symp. 1997, 118, 323-328.

28) Isayev, A. I.; Chan, T. W.; Shimojo, K.; Gmerek, M. Injection-Molding of Semicrystalline Polymers 0.1. Material Characterization. J. Appl. Polym. Sci. 1995, 55 (5), 807-819.

29) Gahleitner, M.; Jaaskelainen, P.; Ratajski, E.; Paulik, C.; Reussner, J.; Wolfschwenger, J.; Neissl, W. Propylene-ethylene random copolymers: Comonomer effects on crystallinity and application properties. J. Appl. Polym. Sci. 2005, 95 (5), 1073-1081.

30) Jeon, K.; Chiari, Y. L.; Alamo, R. G. Maximum Rate of Crystallization and Morphology of Random Propylene Ethylene Copolymers as a Function of Comonomer Content up to 21 mol \%. Macromolecules 2008, 41 (1), 95-108.

31) Gahleitner, M.; Wolfschwenger, J.; Fiebig, J.; Neissl, W. Influence of nucleants on the formation of shear-induced structures in polypropylene. Macromol. Symp. 2002, 185, 77-87.

32) Zimmermann, H. J.; Hoechst, A. G. Structural analysis of random propyleneethylene copolymers. J. Macromol. Sci., Part B: Phys. 1993, 32 (2), 141-161.

33) Laihonen, S.; Gedde, U. W.; Werner, P. E.; Westdahl, M.; Jääskeläinen, P.; Martinez-Salazar, J. Crystal structure and morphology of melt-crystallized poly(propylene-stat-ethylene) fractions. Polymer 1997, 38 (2), 371-377.

34) Alamo, R. G.; VanderHart, D. L.; Nyden, M. R.; Mandelkern, L. Morphological Partitioning of Ethylene Defects in Random Propylene-Ethylene Copolymers. Macromolecules 2000, 33 (16), 6094-6105.

35) Ma, Z.; Fernandez-Ballester, L.; Cavallo, D.; Gough, T.; Peters, G. W. M. High-Stress Shear-Induced Crystallization in Isotactic Polypropylene and Propylene/Ethylene Random Copolymers. Macromolecules 2013, 46 (7), 2671-2680.

36) Housmans, J.-W.; Peters, G. W. M.; Meijer, H. E. H. Flow-induced crystallization of propylene/ethylene random copolymers. J. Therm. Anal. Calorim. 2009, 98 (3), 693.

37) Fatou, J. G. Melting temperature and enthalpy of isotactic polypropylene. Eur. Polym. J. 1971, 7 (8), 1057-1064.

38) Monasse, B. Polypropylene nucleation on a glass fibre after melt shearing. J. Mater. Sci. 1992, 27 (22), 6047-6052.

39) Monasse, B. Nucleation and anisotropic crystalline growth of polyethylene under shear. J. Mater. Sci. 1995, 30 (19), 5002-5012. 
40) Eder, G.; Janeschitz-Kriegl, H. Crystallization. In Processing of Polymers; Meijer, H. E. H., Ed.; Wiley-VCH: New York, 1997; Vol. 18, pp 269-342.

41) Stadlbauer, M.; Janeschitz-Kriegl, H.; Eder, G.; Ratajski, E. New extensional rheometer for creep flow at high tensile stress. Part II. Flow induced nucleation for the crystallization of iPP. J. Rheol. 2004, 48 (3), 631-639.

42) Van Krevelen, D. W. Properties of Polymers; Elsevier: Amsterdam, 1990.

43) Alexander, L. B. E.; Chalmers, B.; Kurmhansl, J. X-ray Diffraction Methods in Polymer Science; Wiley-Interscience: 1969.

44) Van Krevelen, D. W.; Te Nijenhuis, K. Properties of Polymers: Their Correlation with Chemical Structure; Their Numerical Estimation and Prediction from Additive Group Contributions; Elsevier: 2009.

45) De Rosa, C.; Auriemma, F.; de Ballesteros, O. R.; Resconi, L.; Camurati, I. Crystallization Behavior of Isotactic Propylene-Ethylene and PropyleneButene Copolymers: Effect of Comonomers versus Stereodefects on Crystallization Properties of Isotactic Polypropylene. Macromolecules 2007, 40 (18), 6600-6616.

46) Sanchez, I. C.; Eby, R. K. Thermodynamics and Crystallization of Random Copolymers. Macromolecules 1975, 8 (5), 638-641.

47) Alamo, R. G.; Ghosal, A.; Chatterjee, J.; Thompson, K. L. Linear growth rates of random propylene ethylene copolymers. The changeover from $\gamma$ dominated growth to mixed $(\alpha+\gamma)$ polymorphic growth. Polymer 2005, 46 (20), 8774-8789.

48) Cheng, S. Z. D.; Janimak, J. J.; Zhang, A. Q.; Hsieh, E. T. Isotacticity Effect on Crystallization and Melting in Polypropylene Fractions 0.1. CrystallineStructures and Thermodynamic Property Changes. Polymer 1991, 32 (4), 648-655.

49) Laihonen, S.; Gedde, U. W.; Werner, P. E.; Martinez-Salazar, J. Crystallization kinetics and morphology of poly(propylene-statethylene) fractions. Polymer 1997, 38 (2), 361-369.

50) Hosier, I. L.; Alamo, R. G.; Lin, J. S. Lamellar morphology of random metallocene propylene copolymers studied by atomic force microscopy. Polymer 2004, 45 (10), 3441-3455.

51) Hosoda, S.; Hori, H.; Yada, K.; Nakahara, S.; Tsuji, M. Degree of comonomer inclusion into lamella crystal for propylene/olefin copolymers. Polymer 2002, 43 (26), 7451-7460.

52) Mileva, D.; Androsch, R.; Radusch, H.-J. Effect of cooling rate on meltcrystallization of random propylene-ethylene and propylene-1-butene copolymers. Polym. Bull. 2008, 61 (5), 643-654.

53) Somani, R. H.; Yang, L.; Hsiao, B. S.; Agarwal, P. K.; Fruitwala, H. A.; Tsou, A. $\mathrm{H}$. Shear-induced precursor structures in isotactic polypropylene melt by in-situ rheo-SAXS and rheo-WAXD studies. Macromolecules 2002, 35 (24), 9096-9104. 


\section{SUPPORTING INFORMATION}

\section{Effect of Random Ethylene Comonomer on Relaxation of Flow-Induced Precursors in Isotactic Polypropylene}

Benjamin Schammé $\dagger \S$, Eric Dargent $\S$, Lucia Fernandez-Ballester $\dagger *$

+ Department of Mechanical and Materials Engineering and Nebraska Center for Materials and Nanoscience,, University of Nebraska at Lincoln, Lincoln, Nebraska 68588, United States.

$\S$ UNIROUEN Normandie, INSA Rouen, CNRS, Groupe de Physique des Matériaux, Normandie Univ., 76000 Rouen, France

Morphological maps of RACO3 and RACO7

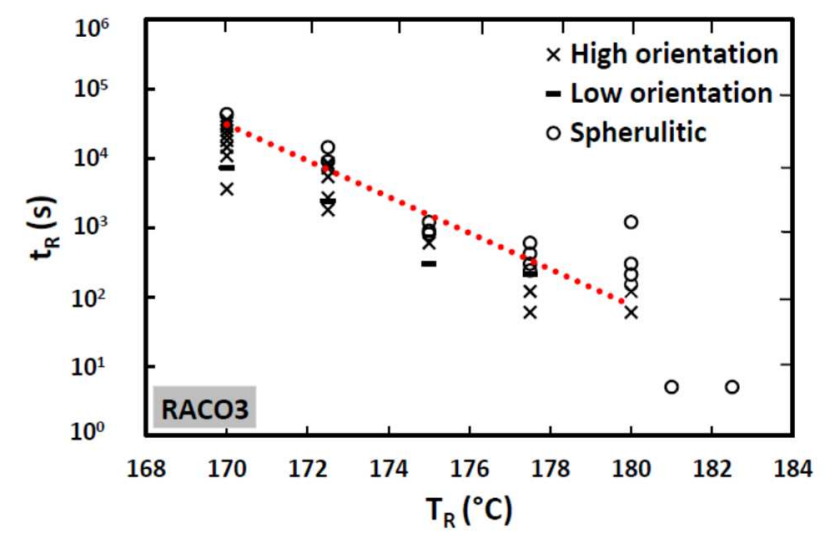

Figure S1. RACO3 morphological map for relaxation experiments. Dashed line corresponds to a linear fit of the calculated critical relaxation times $t^{*}$. 


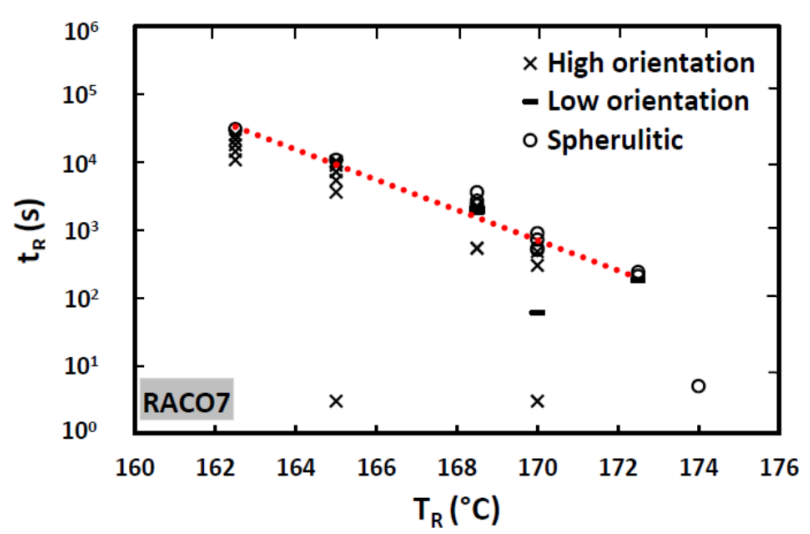

Figure S2. RACO7 morphological map for relaxation experiments. Dashed line corresponds to a linear fit of the calculated critical relaxation times t*.

\section{Estimation of melting enthalpy of copolymer crystals}

The melting enthalpy of copolymer crystals $\Delta \mathrm{H}_{\text {cryst,cop, },}$ estimated using the excess free energy $\varepsilon$ assumed a linear relationship $\Delta \mathrm{H}_{\text {cryst,cop }}=\Delta \mathrm{H}_{\text {cryst,homo }}-\varepsilon \mathrm{X}_{\mathfrak{c}}$, where $\mathrm{X}_{\mathrm{c}}$ is the mole fraction of ethylene co-units in the crystal. Data for $\mathrm{X}_{\mathrm{c}}$ was extracted from a copolymer study by Alamo et $a l .{ }^{1}$, excess free energy $\varepsilon \sim 2.94 \mathrm{~kJ} / \mathrm{mol}$ was obtained from previous work by the same author, ${ }^{2}$ and $8.7 \mathrm{~kJ} / \mathrm{mol}$ was used for $\Delta \mathrm{H}_{\text {cryst,homo. }} \Delta \mathrm{H}_{\text {cryst,RACO3 }}$ (with $3.4 \%$ ethylene) was taken as the average of the values calculated for $2.2 \%$ and $4.59 \%$, and $\Delta \mathrm{H}_{\text {cryst,RACOy }}$ (with $7.3 \%$ ethylene) was taken as that calculated for $7.47 \%$ (Table S1) .

\begin{tabular}{|c|c|c|}
\hline $\begin{array}{c}\text { Ethylene content } \\
(\mathrm{mol} \%)\end{array}$ & $\mathrm{X}_{\mathrm{c}}{ }^{1}$ & $\begin{array}{c}\Delta \mathrm{H}_{\text {cryst,cop, } \varepsilon}=\Delta \mathrm{H}_{\text {cryst,homo }}-\varepsilon \mathrm{X}_{\mathrm{c}} \\
(\mathrm{kJ} / \mathrm{mol})\end{array}$ \\
\hline 0.79 & 0.0035 & 8.69 \\
\hline 2.2 & 0.0103 & 8.67 \\
\hline 3.4 & & 8.66 \\
\hline 4.59 & 0.0202 & 8.64 \\
\hline 7.47 & 0.031 & 8.61 \\
\hline
\end{tabular}

Table S1. Calculations for estimating $\Delta \mathrm{H}_{\text {cryst,cop, }, \text {. }}$ 


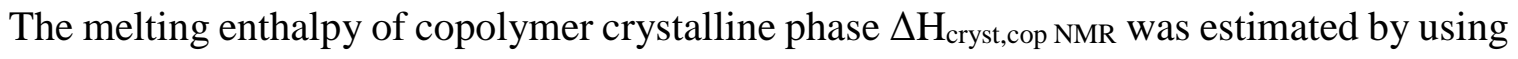
${ }^{13} \mathrm{C}$ NMR crystallinity and experimental heat of fusion $\left(\Delta \mathrm{H}_{\mathrm{cop}}\right)$ measured by Alamo et al. (Table S2). The enthalpy value for the $0.79 \%$ copolymer (considered the homopolymer here) is somewhat smaller than $8.7 \mathrm{~kJ} / \mathrm{mol}(=209 \mathrm{~J} / \mathrm{g})$, so all enthalpy values were normalized to the reference of 8.7 $\mathrm{kJ} / \mathrm{mol}$ by assessing the relative decrease in enthalpy caused by comonomer (denoted as ratio " $\mathrm{r}$ " in Table S2). Note that due to the quasi-crystalline nature of flow-induced precursors, the enthalpy of fusion is in fact expected to be lower (for example, $8.7 \mathrm{~kJ} / \mathrm{mol}$ would be an overestimation for homopolymer precursors) but the magnitude of that difference is unknown. Thus, in the present work, $8.7 \mathrm{~kJ} / \mathrm{mol}$ has been used as the reference for the iPP homopolymer.

\begin{tabular}{|c|c|c|c|c|c|}
\hline $\begin{array}{c}\text { Ethylene } \\
\text { content } \\
(\mathrm{mol} \%)\end{array}$ & $\begin{array}{c}\text { NMR } \\
\text { crystallinity } \\
(\%)^{1}\end{array}$ & $\begin{array}{c}\Delta \mathrm{H}_{\text {cop }} \\
(\mathrm{J} / \mathrm{g})\end{array}$ & $\begin{array}{c}\Delta \mathrm{H}_{\text {cryst,cop }}=\Delta \mathrm{H}_{\text {cop }} / \mathrm{X}_{\mathrm{c}} \\
(\mathrm{J} / \mathrm{g})\end{array}$ & $\begin{array}{c}r=\Delta \mathrm{H}_{\text {cryst,cop }} / \\
\Delta \mathrm{H}_{\text {cryst,0.79\% }}\end{array}$ & $\begin{array}{c}\Delta \mathrm{H}_{\text {cryst,cop NMR }}=8.7 \mathrm{~kJ} / \mathrm{mol} * r \\
(\mathrm{~kJ} / \mathrm{mol})\end{array}$ \\
\hline 0.79 & 0.66 & 92 & 139.4 & 1.00 & 8.7 \\
\hline 2.2 & 0.65 & 84 & 129.2 & 0.93 & 8.1 \\
\hline 3.4 & & & 107.9 & 0.77 & 7.4 \\
\hline 4.59 & 0.63 & 68 & 105.2 & 0.75 & 6.7 \\
\hline 7.47 & 0.58 & 61 & & & 6.6 \\
\hline
\end{tabular}

Table S2. Calculations for estimating $\Delta \mathrm{H}_{\text {cryst,cop,NMR. }}$ 


\section{Differential scanning calorimetry}

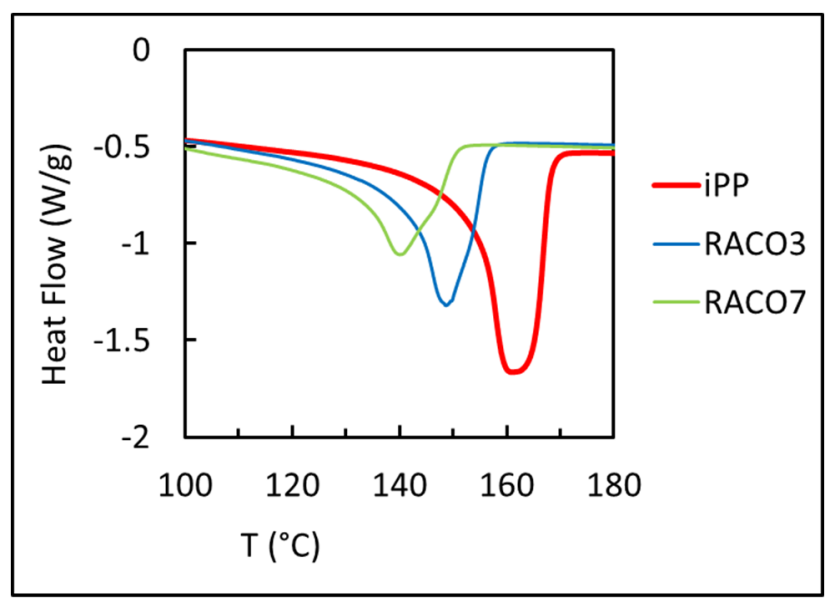

Figure S3. Melting endotherms at a heating rate of $10^{\circ} \mathrm{C} / \mathrm{min}$

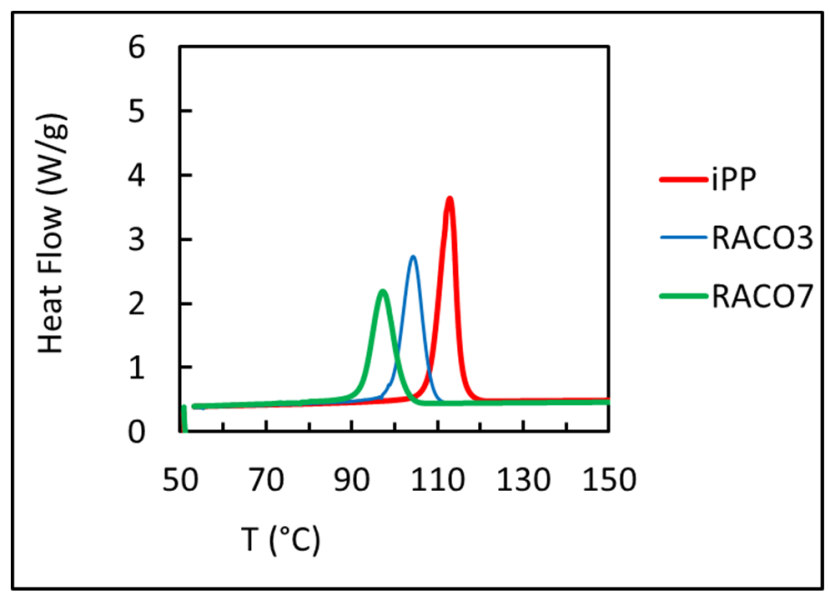

Figure S4. Melting exotherms at a cooling rate of $10^{\circ} \mathrm{C} / \mathrm{min}$

\section{$\underline{\text { References }}$}

1 R. G. Alamo, D. L. VanderHart, M. R. Nyden, and L. Mandelkern, Macromolecules 33, 6094 (2000).

2 R. G. Alamo, A. Ghosal, J. Chatterjee, and K. L. Thompson, Polymer 46, 8774 (2005). 